\title{
O PAPEL DA U.T.I. NO TRATAMENTO DAS FÍSTULAS ENTÉRICAS
}

THE ROLE OF INTENSIVE CARE UNIT IN THE THERAPY OF INTESTINAL FISTULAS

Isac Jorge Filho

Chefe do Serviço de Gastroenterologia da Santa Casa de Ribeirão Preto e Doutor em Cirurgia pela Faculdade de Ciências Médicas da Santa Casa de São Paulo.

CorRespondência： Av. Nove de julho, 1777 - CEP: 14015-170 - Ribeirão Preto - SP; Fone: (016) 610-9371; Fax: (016) 636-2681

JORGE FILHO I. O papel da U.T.I. no tratamento das fístulas entéricas. Medicina, Ribeirão Preto, 31: 568-576, out./dez. 1998.

RESUMO: As fístulas entéricas continuam representando complicações pós-operatórias, extremamente graves e respondem por relevante mortalidade. Seu tratamento depende de um trabalho planificado, executado por equipe multiprofissional. Medidas clínicas e cirúrgicas se complementam, já que, apesar da prioridade para o tratamento conservador, as intervenções cirúrgicas podem ser indispensáveis como medidas auxiliares, principalmente no combate à sepse. Ao longo do tratamento, o concurso do intensivista pode ser necessário, principalmente na fase inicial, quando o paciente pode apresentar importantes distúrbios hidroeletrolíticos, sépticos, ou cardiorrespiratórios. Em mais da metade dos pacientes, as fístulas se fecham espontaneamente com o tratamento conservador. $O$ tratamento operatório definitivo, para o fechamento da fístula, fica reservado para os casos em que falharam os esforços para o fechamento espontâneo, mas só será realizado após o completo desaparecimento da sepse abdominal.

UNITERMOS: Fístula Intestinal. Cirurgia. Unidades de Terapia Intensiva.

\section{INTRODUÇÃO}

São indiscutíveis e claros os históricos avanços obtidos no tratamento dos pacientes com fístulas digestivas. No entanto, essas comunicações patológicas do tubo digestivo com o meio externo, ou com o interior de vísceras ocas, continuam se constituindo em um dos mais graves problemas enfrentados pelo cirurgião $0^{(1)}$.

Em serviços de Cirurgia Geral ou de Cirurgia Digestiva, de $75 \%$ a $85 \%$ das fístulas são pós-operatórias ${ }^{(2)}$, tendo mais da metade delas origem no intestino delgado. A mortalidade decorrente de complicações relacionadas com fístulas intestinais é, ainda, muito alta, variando de $6,5 \%$ a $48 \%{ }^{(2 / 9)}$. Estudos recentes mostram taxas de até $37 \%{ }^{(10)}$, enquanto a mé- dia de mortalidade para a maioria dos procedimentos cirúrgicos, eletivos gira, atualmente, em torno de $2 \%{ }^{(11)}$.

$\mathrm{O}$ tratamento de uma fístula digestiva, principalmente se de alto débito, é procedimento complexo, que exige trabalho multiprofissional e condutas dinâmicas e particularizadas. Medidas clínicas e cirúrgicas não competem entre si, mas, antes, se somam em diferentes fases do tratamento, na busca do objetivo final, que é o de se obter o fechamento da fístula e conseguir a recuperação integral do paciente.

Em diferentes situações, os comprometimentos orgânicos determinados por fístulas entéricas justificam plenamente a necessidade de cuidados intensivos, buscando a retomada de equilíbrios perdidos para que se dê a oportunidade para a resolução espontânea ou operatória do processo fistuloso. 


\section{REPERCUSSÕES DAS FÍSTULAS DE ALTO DÉ- BITO}

As fístulas que drenam $500 \mathrm{~mL}$, ou mais, de secreções digestivas, a cada vinte e quatro (24) horas, são consideradas de alto débito. Isso é muito comum nas fístulas jejunoileais, principalmente nas mais altas, podendo o débito diário ultrapassar dois litros. A espoliação determinada por essas grandes perdas ocasiona importantes impactos hidroeletrolíticos e nutricionais.

As perdas líquidas através da fístula não podem ser encaradas como simples perdas hidroeletrolíticas a serem repostas. Na realidade, o que se perde é um material de alta complexidade, contendo substâncias importantes para o organismo. A composição do líquido perdido varia muito, em função de fatores como a localização da fístula, o tamanho do orifício interno, o número de fístulas e a ação de estímulos secretórios. De qualquer forma, a constituição básica é sempre representada por uma solução aquosa, contendo eletrólitos, enzimas digestivas, fatores tróficos, outras substâncias orgânicas e quantidades variáveis de células de descamação. Em fístulas de baixo débito, essas perdas são compensáveis com certa facilidade. No entanto, quando o débito é alto, as perdas são relevantes e concorrem, sem dúvida, para o agravamento do quadro apresentado. Vale chamar atenção para a impacto nutricional nessas condições, já que as enzimas digestivas e as células de descamação, eliminadas para o meio externo, representam grandes perdas de nutrientes, relevantes e graves para um organismo que já se encontra em situação crítica. A situação fica ainda mais grave se o paciente apresenta prévia desnutrição. A gravidade se torna extrema se à desnutrição se soma a sepse que, ao determinar hipercatabolismo, consome ainda mais as já exauridas reservas nutricionais. Assim, é compreensível que sejam relatadas altíssimas taxas de mortalidade nos pacientes sépticos e desnutridos que apresentam fístulas jejunoileais de alto débito ${ }^{(1)}$.

É especialmente neste grupo de fístulas que, com freqüência, o trabalho do intensivista é requerido.

\section{3 - TRATAMENTO DO PACIENTE COM FÍSTULA ENTÉRICA}

\subsection{Aspectos gerais}

É fundamental que se tenha sempre em mente que o que deve ser tratado é o paciente como um todo, e não "a fistula", como se ela fosse uma entidade independente.
As medidas iniciais são de ordem geral, objetivando a recuperação do equilíbrio orgânico, perdido em função das alterações determinadas pela fístula.

As manifestações observadas em pacientes com fístulas entéricas são extremamente variáveis. Entre pequenas fístulas, com baixíssimo débito, sem repercussões clínicas, até formas catastróficas, com sérios distúrbios associados, existe toda uma gama de formas intermediárias. Tal variação explica a necessidade de que o tratamento seja particularizado para cada caso, apesar de seguir um planejamento bási$\mathrm{co}^{(1)}$.

Os princípios gerais que regem a abordagem inicial e o tratamento do paciente com fístula entérica são os seguintes ${ }^{(11)}$ :

a) imediata avaliação das condições gerais, cirúrgicas e do estado nutricional;

b) medidas de recuperação geral, que incluem as correções, por via venosa, dos desequilíbrios hidroeletrolíticos e acidobásicos;

c) suspensão da ingestão oral de alimentos e início de adequado suporte nutricional;

d) estudo do abdômen e da fístula através de métodos de imagem, buscando definir características como: local de origem, trajeto e número de fístulas, presença ou não de abscessos ou corpos estranhos. A Figura 1 mostra a fistulografia de uma fístula entérica jejunal;

e) controle e redução do débito da fístula;

f) prevenção e tratamento das lesões da pele;

g) prevenção e tratamento das complicações metabólicas e sépticas.

A esses princípios vale acrescentar a necessidade de um adequado suporte psicológico, fundamental para um paciente que soma à decepção com a complicação cirúrgica pós-operatória, os problemas do jejum prolongado, da insegurança quanto ao futuro, da alta permanência hospitalar e do desconforto e dor que acompanham o quadro ${ }^{(12,13,14)}$.

\subsection{Metodização do tratamento}

Não obstante haja necessidade de se atentar às características particulares de cada caso, é indispensável que o tratamento das fístulas entéricas seja metodizado, seguindo um plano geral bem elaborado, que pode ser diferenciado em três fases.

Fase I : Medidas gerais de recuperação.

Fase II: Tratamento conservador.

Fase III: Tratamento cirúrgico da fístula, desde que não ocorra fechamento espontâneo na fase II. 


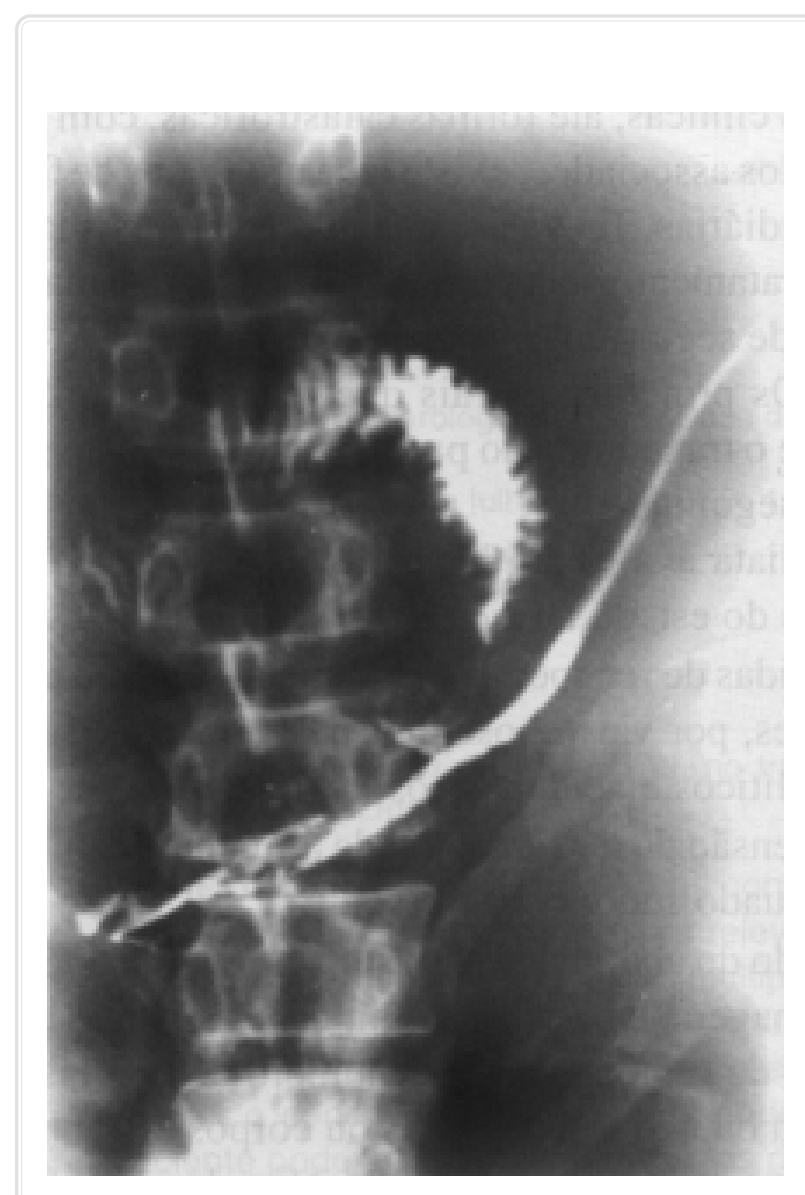

Figura 1 - Aspecto de Fistulografia de fístula jejunal.

\subsubsection{Medidas gerais de recuperação}

As fístulas digestivas, principalmente as de alto débito, determinam importantes, alterações no equilíbrio orgânico. As correções desses desequilíbrios são prioritárias, sendo, nesta fase, que ocorrem as maiores complicações e óbitos.

As principais alterações estão representadas pelos distúrbios dos líquidos corporais (desequilíbrios hidroeletrolíticos, desequilíbrios acidobásicos e desequilíbrios osmóticos), pela presença de sepse, e por eventuais distúrbios cardiorrespiratórios. Esses distúrbios se fazem sentir mais acentuadamente nas primeiras quarenta e oito (48) horas, período de maior instabilidade e risco, e devem ser corrigidos o mais prontamente possível. É também nesta fase que, mais freqüentemente, há necessidade da participação de equipes de intensivistas.

\subsubsection{Correção dos distúrbios dos líquidos corporais}

É fundamental nas fístulas de alto débito. Há necessidade de analisar e corrigir os distúrbios de volume, de composição e de osmolaridade. Implica adequada reposição através da via parenteral, com soluções cristalóides, que devem ser complementadas com colóides, quando a pressão coloidosmótica do plasma estiver muito baixa, com perdas relevantes para o espaço intersticial. Nos pacientes mais graves, é importante que a reposição seja monitorizada, com a utilização da medida da pressão venosa central ou de medidas mais sensíveis, como a utilização do cateter de Swan-Ganz.

Os distúrbios acidobásicos, metabólicos podem ser decorrentes das perdas de ácidos ou bases, dependendo da altura da fístula no tubo digestivo, e da má perfusão tecidual, decorrente da hipovolemia. Nas fístulas jejunoileais, as soluções perdidas são, quase sempre, alcalinas, com importante perda do íon de bicarbonato. Quando os tecidos estão mal perfundidos, a produção de ácidos no metabolismo anaeróbico se soma com a perda de bicarbonato pela fístula, o que responde por acidose metabólica, por vezes muito grave, exigindo tratamento especial, com utilização correta de soluções de bicarbonato ou lactato. Os distúrbios respiratórios do equilíbrio acidobásico são corrigidos através de medidas específicas sobre o aparelho respiratório, que poderão incluir necessidade de máscaras ou respiração assistida.

Os desvios relevantes do equilíbrio dos líquidos corporais levam à má-perfusão tecidual, o que torna contra-indicado o início do suporte nutricional parenteral, antes da correção do déficit perfusional. Por outro lado, tais distúrbios promovem ou mantem o íleo adinâmico, situação que contra-indica o suporte nutricional enteral.

Em décadas passadas, os distúrbios eletrolíticos chegaram a representar a causa maior da alta mortalidade em pacientes com fístulas digestivas. As observações clássicas de Edmunds et al., referentes a cento e cinqüienta e sete (157) pacientes, tratados no período de 1946-1959, relatam vinte e três (23) pacientes com graves distúrbios hidroeletrolíticos, sendo que dezoito (18) deles foram a óbito, ou seja, mortalidade de $78 \%{ }^{(15)}$. Com os avanços obtidos no diagnóstico e tratamento dos distúrbios hidroeletrolíticos, acidobásicos e de osmolaridade, a mortalidade devida fundamentalmente a esses fatores caiu acentuadamente, mas esses distúrbios ainda representam problemas sérios a serem controlados nos pacientes com fístulas de alto débito. 


\subsubsection{Tratamento dos problemas sépticos}

Os problemas sépticos constituem a causa mais comum de morte nos pacientes com fístulas digestivas. Por isso devem ser diagnosticados e tratados o mais precocemente possível. Nesse campo, muitas vezes, há necessidade de medidas cirúrgicas e elas não podem, sob nenhuma hipótese, ser contemporizadas. Hollender constatou que a mortalidade nas fístulas digestivas, tratadas por seu grupo, esteve, em grande parte, ligada ao retardo na indicação de relaparotomia para tratamento da peritonite pós-operatória e, também, pela execução de anastomoses em meio sépti$\mathrm{co}^{(16,17)}$. Parc et al., analisando quinhentos e vinte e três (523) prontuários de pacientes com fístulas, observaram que, nos casos de peritonite pós-operatória, a mortalidade foi de $18 \%$, quando a intervenção ocorreu antes do quinto dia; $43 \%$, se realizada entre o sexto e o sétimo dia; tendo chegado a $75 \%$, quando a relaparotomia foi realizada após o décimo dia ${ }^{(18)}$.

O diagnóstico de sepse abdominal sempre deve ser procurado quando do aparecimento de sinais sugestivos, como: aumento da freqüência cardíaca; febre elevada no pós-operatório imediato; ́leo adinâmico, prolongado; dor abdominal, relevante, no terceiro ou quarto dia de pós-operatório; elevação de uréia e creatinina no sangue. Nessas situações, exames complementares devem ser utilizados, como radiografias de tórax, ultrassonografias, tomografias e outros. Quando o diagnóstico não é feito até o quinto dia de sepse, ficam mais freqüentes as manifestações de choque séptico, com distúrbios respiratórios, oligúria, acidose metabólica e icterícia. Em alguns pacientes, o quadro caminha de forma catastrófica para insuficiência de múltiplos órgãos e sistemas, com índices elevadíssimos de mortalidade ${ }^{(1)}$.

Muitas vezes, a intervenção cirúrgica, para combater a sepse, é retardada, por se julgar que o paciente está em estado muito crítico para ser operado, principalmente logo após a operação que determinou a fístula. Outras vezes, a operação é retardada por receio de uma laparotomia "branca"(19). Trabalhos têm demonstrado, no entanto, que o risco em operar é menor do que o de não operar, e que, se a relaparotomia é feita antes do desenvolvimento de insuficiências orgânicas múltiplas, o risco de morte após uma laparotomia "branca", não é proibitivo ${ }^{(20)}$.

Já é clássico o reconhecimento de que a utilização de antibióticos, desacompanhada da ação direta sobre o foco infeccioso, não apresenta impacto significante nas taxas de mortalidade por fístulas intestinais ${ }^{(21)}$.
A sepse, nos pacientes com fístulas digestivas, ocorre mais freqüentemente por causas como as relacionadas a seguir.

Peritonite difusa: é determinada pela presença de conteúdo do tubo digestivo na cavidade peritoneal, sendo infecção mista de aeróbios (mais comumente a Escherichia coli) e anaeróbios (principalmente Bacterioides fragilis). Na peritonite difusa, a intervenção cirúrgica é mandatória e urgente, mas visa apenas a peritonite. Consiste em ampla limpeza e lavagem da cavidade, podendo incluir desbridamentos, retirada de corpos estranhos, ressecção e exteriorização de segmentos comprometidos. Não se deve tentar fechar a fístula, cirurgicamente, nessa fase. O uso de antibióticos é fundamental e a escolha deve recair sobre medicamentos capazes de agir sobre flora bacteriana mista.

Abscessos: quando existem evidências de que o processo infeccioso abdominal é circunscrito, ele poderá ser drenado, evitando-se, assim, contaminar o restante da cavidade. Quando os abscessos forem grandes e estiverem em contato com o peritônio parietal, anterior ou lateral, a drenagem cirúrgica poderá ser extra-serosa. Nas outras situações, a drenagem será transparietal. De preferência, são utilizados os drenos tubulolaminares, exteriorizados por contraaberturas amplas. A opção pela drenagem percutânea, dirigida por ultrassonografia ou tomografia, é cada vez maior $^{(22,23)}$. É indispensável que todas as coleções sejam drenadas para que se possa chegar ao balanço nitrogenado positivo e ao fechamento espontâneo do trajeto da fístula ${ }^{(19)}$.

Infecções de parede: as lesões parietais, determinadas pelas secreções eliminadas pelas fístulas, levam à perda tecidual e diminuição da resistência à ação das bactérias existentes nas próprias secreções ou vindas do meio ambiente (Figura 2). As infecções, assim instaladas, podem comprometer pele e subcutâneo (determinando uma celulite), fáscia e aponeurose (levando a fasciíte) e músculos (levando a uma miosite), com comprometimento maior ou menor de cada estrutura. A forma mais grave é a gangrena gasosa clostridiana. $\mathrm{O}$ tratamento das infecções parietais importantes inclui adequada antibioticoterapia, que depende do agente etiológico; amplos desbridamentos e lavagens; e, às vezes, recursos excepcionais, como a oxigenoterapia hiperbárica.

Outras infecções: infecções pulmonares, flebites e infecções urinárias podem estar presentes, participando do quadro séptico, principalmente nos pacientes debilitados e com falências múltiplas. É fundamental que tais infecções mereçam cuidados adequados. 


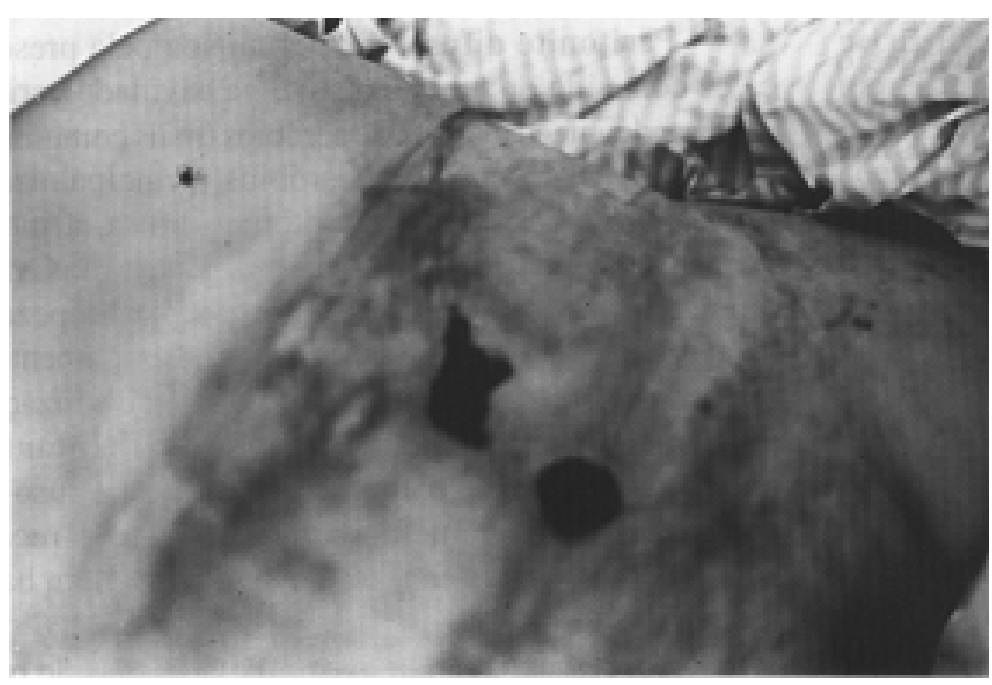

Figura 2 - Corrosão e infecção da parede abdominal por fístulas entéricas de alto débito.

\subsubsection{Correção dos distúrbios cardiorrespi- ratórios}

Presentes principalmente nos pacientes idosos e nos que já apresentavam, no pré-operatório, doenças cardiorrespiratórias. Muitas vezes, requerem tratamento especializado intensivo, com monitorização.

\subsubsection{Tratamento conservador}

Tem como objetivo final o fechamento espontâneo da fístula. Para isso são necessárias as seguintes condições:

1. equilíbrio dos líquidos corporais;

2. desaparecimento das manifestações sépticas;

3. redução do débito da fístula e, conseqüentemente, das perdas de água, eletrólitos, nutrientes e fatores tróficos;

4. proteção da pele e reparação de suas lesões;

5. adequada oferta de nutrientes que possibilitem o melhor estado nutricional possível, permitindo a reparação tecidual e os processos fibroblásticos e de multiplicação celular que culminarão com o fechamento do trajeto e do orifício fistuloso.

\subsubsection{Manutenção do equilíbrio dos líqüidos corporais}

Os cuidados com o equilíbrio hidroeletrolítico, iniciados na Fase I, equilíbrio acidobásico e equilíbrio osmótico devem ter seqüência ao longo do tratamento clínico das fístulas entéricas. Descuidos na reposição podem levar a novos desequilíbrios, com consequiências graves.

\subsubsection{Tratamento da sepse}

A compensação dos problemas infecciosos, iniciada na primeira fase, não significa desaparecimento total da sepse. Assim, os cuidados e tratamentos de possíveis focos sépticos, os curativos freqüentes e a contínua vigilância quanto à possibilidade de novas infecções devem permanecer ao longo de todo o tratamento.

\subsubsection{Redução do débido da fístula}

Como o alto débito representa importante fator agravante nas fístulas digestivas, em função da espoliação que determina, procedimentos que busquem reduzir as perdas são muito importantes. Dois tipos de medidas são utilizados: a manutenção do paciente em jejum absoluto e o uso de drogas capazes de reduzir as secreções digestivas. Adicionalmente, em determinadas situações, a reinfusão para o tubo digestivo dos líquidos perdidos pela fístula pode ser medida auxiliar com o objetivo de diminuir a espoliação.

Jejum absoluto: tem como finalidade a diminuição do estímulo para as secreções digestivas. Sua utilização está, logicamente, ligada à necessidade de um suporte nutricional parenteral total.

Medicamentos: nas fístulas jejunoielais são utilizados dois tipos de medicamentos: a somatostatina e seus análogos e os bloqueadores de secreção gástrica.

Somatostatina e análogos: a somatostatina é um hormônio natural, capaz de diminuir acentuadamente as secreções digestivas, reduzindo, assim, o débito das fístulas entéricas. Adicionalmente, tem a vantagem de reduzir a motilidade gastrintestinal, o que prolonga o tempo de trânsito, aumentando a absorção intestinal de água e eletrólitos, o que concorre para a diminuição do débito das fístulas. Ysebaert et al. apresentaram uma série consecutiva de vinte e três (23) pacientes com fístulas, cujo tratamento conservador incluiu a somatostatina e o suporte nutricional parenteral total. $\mathrm{O}$ fechamento espontâneo foi conseguido 
em $83 \%$ dos pacientes, com um tempo médio de uso da somatostatina de 13,2 $\pm 7,0$ dias. Não houve mortalidade na série ${ }^{(24)}$. Os problemas com relação ao uso da somatostatina estão ligados ao uso exclusivamente por via venosa e à sua meia-vida muito curta, o que exige infusão contínua. A busca de soluções para esses problemas levou à síntese de análogos da somatostatina, como o octreótide, um octapeptídeo sintético, que apresenta efeitos semelhantes aos da somatostatina, tendo, porém, meia-vida prolongada, o que lhe confere maior tempo de ação e maior potência farmacológica. Outra importante vantagem é o seu uso subcutâneo, o que torna muito prática sua utilização. Nubiola et al., trataram vinte e sete (27) pacientes com fístulas enterocutâneas pós-operatórias, com nutrição venosa, total e octreótide (100 mcg a cada oito (8) horas, por via subcutânea) tendo obtido redução média de $55 \%$ do débito das fístulas, nas primeiras vinte e quatro (24) horas. A taxa de fechamento espontâneo foi de $77 \%$, após um período de 5,8 $\pm 2,7$ dias de tratamento. Além de concluir pela eficiência do tratamento, os autores chamaram atenção para a diminuição no tempo de internação, já que o tempo para fechamento espontâneo, utilizando apenas a nutrição venosa total, sem o uso de octreótide, é da ordem de quatro a seis (4-6) semanas ${ }^{(25)}$. Outros autores têm publicado suas experiências, concluindo pela eficiência do octreótide, no tratamento das fístulas enterocutâneas ${ }^{(26,27)}$.

Bloqueadores da secreção gástrica: aliam à diminuição da secreção o efeito de prevenção das úlceras de estresse e lesões agudas da mucosa gástrica. Além disso, os bloqueadores de secreção gástrica têm um efeito indireto na redução do volume de secreção pancreática, por diminuir a acidez do suco gástrico que chega ao duodeno.

Reinfusão do líquido fistuloso: quando o tubo digestivo é funcionante e o débito da fístula é alto, pode ser interessante a reinfusão dos líquidos perdidos para a luz digestiva. Isso é possível através de sonda gástrica nas fístulas ileais baixas. Nas fístulas jejunais altas o procedimento requer a passagem da sonda distalmente à fístula. $\mathrm{O}$ procedimento tem como objetivo devolver ao tubo digestivo as secreções perdidas. Não é um método de redução do débito da fístula, mas reduz a espoliação.

\subsubsection{Cuidados com a pele}

A ação das secreções digestivas sobre a pele determina importantes lesões. Escoriações, maceração e digestão da pele podem levar a relevante perda tecidual. São lesões que trazem intenso sofrimento físico e psicológico ao paciente, além de agravarem seu quadro geral e infeccioso. Daí a necessidade de se adotarem medidas que busquem, de um lado, impedir a chegada das secreções até a pele e, de outro, recobrir o tegumento com algum tipo de protetor que funcione como barreira à ação cutânea dos líquidos drenados pela fístula.

Os agentes protetores, utilizados, são os mais variados, indicando a dificuldade encontrada para a solução do problema, especialmente nas fístulas de alto débito. Pomadas de alumínio, "spray" de silicone e pasta de Karaya, são alguns dos materiais protetores usados. Placas de Stomahesive ${ }^{\circledR}$ e pasta de bentonita/colestiramina têm sido utilizadas no mesmo sentido $^{(28)}$. O Stomahesive ${ }^{\circledR}$ é um derivado de pectina, gelatina, carboximetilcelulose e poliisobutileno, apresentado na forma de placas, que podem ser preparadas de modo a cobrir a região perifistular, deixando, no centro, um orifício exatamente do tamanho do orifício externo da fístula. Para a colocação da placa é indispensável ter a pele bem seca e limpa, e, se possível, fazer uma delicada tricotomia. O recobrimento das áreas expostas à ação das secreções digestivas, por meio de material protéico biológico tem oferecido, também, resultados compensadores para a proteção da área perifistular, sendo os resultados particularmente interessantes com aplicação de uma camada de claras de ovos em toda a área que toma contato com as secreções vertidas pela fístula ${ }^{(29)}$.

Fístulas múltiplas, fístulas expostas e fístulas de alto débito são as que apresentam maiores dificuldades para a proteção da pele.

Nas fístulas de débito relevante e com trajeto fibroso bem definido, é procedimento importante a sondagem do trajeto fistuloso com um cateter cujo diâmetro ocupe toda a luz do orifício externo da fístula e que seja introduzido até as proximidades do orifício interno, sem penetrar na alça intestinal. Pelo cateter, assim colocado, pode ser feita aspiração intermitente com bomba termostática. Assim, frequientemente, se consegue impedir que as secreções digestivas extravasem para a pele. À medida que o orifício externo vai se fechando, o cateter de drenagem vai sendo substituído por outro mais fino, até a retirada final. Quando o orifício externo é muito amplo, pode-se utilizar um cateter, tipo Folley, insuflando o balonete logo abaixo do orifício externo e, com isso, ocluindo totalmente o trajeto fistuloso ${ }^{(12)}$. 
Com relação aos curativos nas regiões banhadas por secreções digestivas, a melhor conduta é deixar a pele descoberta, já que o embebimento de gazes e compressas mantém os sucos digestivos por mais tempo em contato com a pele, agravando as lesões. Quando a utilização de coberturas for indispensável, elas devem ser pouco espessas e trocadas com freqüência, a medida que fiquem muito embebidas ${ }^{(30)}$.

\subsubsection{Suporte nutricional}

O suporte nutricional nos pacientes com fístulas entéricas busca permitir a restauração das proteínas tissulares, a melhora das defesas imunitárias, a cicatrização dos tecidos lesados, o ganho de peso, o aumento da força muscular e a melhora do estado geral. Tudo isso depende de um balanço nitrogenado positivo, o que, nos pacientes com fístulas de alto débito, dificilmente é alcançado, especialmente se o paciente estiver em sepse. De qualquer forma, mesmo que não se consiga balanço nitrogenado positivo a oferta de nutrientes é indispensável, na medida que cada nutriente incorporado economiza a utilização de um outro, que seria retirado da própria massa corporal.

O suporte nutricional deve ser iniciado a partir do momento em que o paciente recuperou sua perfusão tecidual. A via inicial é, preferentemente, a parenteral, podendo ou não passar para enteral, de acordo com os critérios abaixo apontados.

O suporte nutricional parenteral, ao permitir o repouso digestivo, determina duas consequiências antagônicas: permite a diminuição do débito da fístula mas não nutre o epitélio do tubo digestivo. No entanto, em muitas situações, é o suporte nutricional de escolha, embora seja de controle mais difícil e esteja sujeito a complicações mais graves que as do suporte enteral. As fístulas jejunoileais apresentam, via de regra, débito relevante, o que justifica a opção inicial pela via parenteral.

A utilização da via enteral para o suporte nutricional de pacientes com fístulas digestivas depende de três condições: a adequada permeabilidade e motilidade do tubo digestivo, a possibilidade de impedir que os nutrientes saiam pela fístula, e a tolerância às dietas. Nas fístulas entéricas, é utilizada em situações de baixo débito e peristaltismo normal.

\subsubsection{Fechamento espontâneo}

O objetivo final do tratamento conservador é o fechamento espontâneo da fístula entérica. Nas dife- rentes estatísticas, isso tem sido alcançado em níveis que variam de $9 \%$ a $80 \%$. Quando são analisados apenas os sobreviventes, até $90 \%$ dos pacientes podem ter fechamento espontâneo, dentro de quatro a seis semanas $^{(11)}$.

Uma análise histórica demonstra que a introdução racional do suporte nutricional teve forte impacto na melhora dos resultados quanto ao fechamento espontâneo das fístulas entéricas. Assim, Himal et al. encontraram $27 \%$ de fechamentos espontâneos antes da introdução do suporte nutricional parenteral e $56 \%$ após sua introdução ${ }^{(4)}$. Soeters et al., analisando retrospectivamente seu material, observaram que a taxa de fechamento espontâneo triplicou a partir do período em que o suporte nutricional parenteral passou a ser utilizado ${ }^{(21)}$. As estatísticas de autores que apresentam grandes séries de pacientes reportam aumento nas taxas de fechamento espontâneo (40\% a $70 \%)^{(7,21,31)}$. A introdução da somatostina e seus análogos tem melhorado os índices de fechamento espontâneo e diminuído claramente o tempo de tratamento e de internação ${ }^{(24,25,26)}$. Paran et al. obtiveram uma taxa de fechamento espontâneo de $72 \%$ com um período médio de tratamento de onze (11) dias, utilizando octreótide ${ }^{(27)}$.

\subsubsection{Fatores limitantes do fechamento espon- tâneo}

O fechamento espontâneo de uma fístula jejunoileal é limitado por uma série de fatores. Os principais estão relacionados na Tabela I. A importância de se identificarem claramente tais fatores está ligada à possibilidade de conseguir seu afastamento ou compensação. Quando isso for impossível, o conhecimento da existência de fatores limitantes do fechamento será um importante dado auxiliar na escolha do momento propício de renunciar ao tratamento clínico exclusivo, incluindo, então, o tratamento cirúrgico, sem postergações desnecessárias e prejudiciais, desde que os problemas sépticos estejam superados.

\subsubsection{Tempo de tratamento conservador}

Como um contingente variável de fístulas jejunoileais não se fecha espontaneamente, é importante que se defina por quanto tempo o tratamento conservador deve ser mantido sem que a fístula se feche. $\mathrm{Na}$ experiência da maioria dos autores, fístulas que não se fecham em até quatro a seis semanas de tratamento clínico corretamente executado, provavel- 
Tabela I - Fatores limitantes do fechamento espontâneo das fístulas entéricas, pós-operatórias ${ }^{(14)}$

- Idade superior a sessenta e cinco (65) anos

- Débito da fístula superior a $500 \mathrm{~mL} / \mathrm{dia}$

- Fístulas múltiplas

- Fístulas próximas ao ligamento de Treitz

- Fístulas por doenças malignas

- Fístulas por doenças inflamatórias

- Fístulas pós-irradiação

- Fístulas labiadas, diretas ou em evisceração

- Fístulas com disjunção anastomótica

- Fístulas com síndrome do intestino curto

- Fístulas internas

- Presença de corpo estranho

- Obstrução distal à fístula

- Lojas e/ou coleções no trajeto fistuloso

- Desnutrição

- Uso de drogas inibidoras da cicatrização

mente não se fecharão sem a utilização de recursos cirúrgicos. Trata-se, evidentemente, de uma regra geral, o que significa dizer que a análise particularizada deve sempre ser levada em conta. Para a maioria dos pacientes, as chances de que uma fístula se feche espontaneamente após seis semanas de correto tratamento conservador se torna muito pequena, mas, em alguns pacientes, com fístulas de baixo débito, sem repercussão clínica, as medidas conservadoras podem ser mantidas por mais tempo. Não são raros os casos de pacientes que recebem alta hospitalar, com fístula ainda aberta, de débito muito baixo, sendo mantidos com dieta oral e acabando por obter fechamento total após algumas semanas. A situação de pacientes com débito médio ou alto, após seis semanas de tratamento conservador é, no entanto, diferente. Após esse tempo, e na ausência de sinais inflamatórios, intraabdominais, o tratamento cirúrgico deve ser instituído.

\section{QUAIS AS INDICAÇÕES PARA O TRATAMENTO DE UM PACIENTE COM FÍSTULA ENTÉRICA, EM UNIDADE DE TERAPIA INTENSIVA?}

Pacientes com fístulas de baixo débito, sem comprometimento marcante do estado geral, não necessitam de cuidados intensivos. As indicações de tratamento em U.T.I. são, principalmente, as enumeradas a seguir.

1. fístulas de alto débito, com relevantes alterações no equilíbrio dos líquidos corporais;

2. fístulas com manifestações sépticas importantes;

3. fístulas com condições associadas, que requeiram tratamento intensivo. Entre essas situações, podemos incluir distúrbios cardiorrespiratórios e as falências orgânicas em geral.

De um modo geral, o tratamento de uma fístula complicada é prolongado e não se justifica que seja feito integralmente na U.T.I. Assim, resolvidas as situações que determinaram o tratamento intensivo, o doente deve voltar para sua unidade de internação, onde continuará seu tratamento até possibilidade de alta hospitalar.

JORGE FILHO I. The role of intensive care unit in the therapy of intestinal fistulas. Medicina, Ribeirão Preto, 31: 568-576, oct./dec. 1998.

ABSTRACT: Intestinal fistulas (IF) are defined as abnormal communications between two hollow organs or between a hollow organ and the skin. When a IF is diagnosed, a high rate of morbidity and lengthy hospitalization can be anticipated. The successful management of a highoutput IF is better accomplished by a multidisciplinary and intensive care approach following an organized treatment plan, including infections, correction of patient's volume, electrolytes, acidbase deficits and sttoping oral intake and instituting enteral or parenteral nutrition, in order to prevent further losses and malnutrition. In more than $50 \%$ of patients there is a spontaneous closure of the IF. However, definitive surgical closure should be performed if a high-output IF still remains after 6-8 weeks from the inicial event.

UNITERMS: Intestinal Fistula. Surgery. Intensive Care Units. 


\section{REFERÊNCIAS BIBLIOGRÁFICAS}

1 - JORGE FILHO I \& TAKAHASHI PK. Fístulas entéricas pósoperatórias: quando reoperar? Editado pelo Colégio Brasileiro de Cirurgiões 1998. (No prelo)

2 - BERRY SM \& FISCHER JE. Enterocutaneous fistulas. Curr Prob Surg 31: 471-566, 1994.

3 - CAMPOS ACL et al. Suporte nutricional no tratamento das fístulas jejunoileais. Rev Bras Nutr Clin 4: 86-87, 1989.

4 - HIMAL HS et al. The importance of adequate nutrition in closure of small intestinal fistulas. Br J Surg 61: 724-729, 1974.

5 - HOLLENDER LF et al. Les fistules postopératoires de l'intestin grêle. Réflexions à propos de 52 observations. Ann Gastroenterol Hépatol 17: 447-452, 1981.

6 - LEVY E et al. High-outpout external fistulae of the small bowel: management with continous enteral nutrition. $\mathbf{B r} \mathbf{J}$ Surg 76: 676-681, 1989.

7 - MacFADYEN Jr VB et al. Management of gastrointestinal fistulas with parenteral hyperalimentation. Surgery $\mathbf{7 4}$ : 100-105, 1973.

8 - MAILLET $P$ et al. Les fistules externes de l'intestin grêle. Rapport 77iéme Congrès Français de Chirurgie. Masson, Paris, 1977.

9 - NASSOS TP \& BRAASCH JW. External small bowel fistulas. Current treatment and results. Surg Clin North Am 51: 687-692, 1971

10 - SCHEIN M \& DECKER GA. Postoperative external alimentary tract fistulas. Am J Surg 161: 435-438, 1991.

11 - CAMPOS ACL et al. Factors influencing outcome in patients with gastrointestinal fistula. Surg Clin North Am 76: 1191-1198, 1996.

12 - JORGE FILHO I. Fístulas digestivas. In: RIELLA MC. Suporte nutricional parenteral e enteral. $2^{a}$ ed., Guanabara Koogan, Rio de Janeiro, p.323-349, 1993.

13 - JORGE FILHO I. Fístulas digestivas pós-operatórias. In: JORGE FILHO I; ANDRADE JI \& ZILIOTTO JÚNIOR A. Cirurgia geral: pré e pós-operatório. Atheneu, São Paulo, p.314-339, 1995.

14 - JORGE FILHO I. Fatores limitantes do fechamento espontâneo das fístulas digestivas. Rev Soc Bras Nutr Parent 2: 28-36, 1985.

15 - EDMUNDS LH et al. External fistulas arising from the gastrointestinal tract. Ann Surg 152: 445-471, 1960.

16 - HOLLENDER LF et al. Les fistules postopératoires de le intestine grêle. Réflexions à propos de 52 observations. Ann Gastroenterol Hepatol 17: 447-452, 1981

17 - HOLLENDER L et al. Postoperative fistulas of the small intestine: Therapeutics principles. World J Surg 7: 474480, 1983.
18 - PARC R et al. Les suites opératoires précoces des résections intestinales suivies d'anastomoses colo-coliques ou colo-rectales. Manifestations cliniques et biologiques des complications anastomotiques. Déductions thérapeutiques. A propos de 523 observations. Ann Chir 35: 69-76, 1981.

19 - RUBELOWSKY J \& MACHIEDO GW. Reoperative versus conservative management for gastrointestinal fistulas. Surg Clin North Am 71: 147-157, 1991.

20 - MACHIEDO G et al. Reoperation for sepsis. Am Surg 51: 149-154, 1985

21 - SOETERS P et al. Review of 404 patients with gastrointestinal fistulas: Impact of parenteral nutrition. Ann Surg 190: 189-202, 1979

22 - ERCOLI FR et al. Percutaneous catheter drainage of abscess associated with enteric fistulae. Am Surg 54: 4549, 1988.

23 - GERZOF $S$ et al. Percutaneous catheter drainage of abdominal abscesses. A five year experience. $\mathbf{N}$ Engl $\mathbf{J}$ Med 305: 653-657, 1981

24 - YSEBAERT D et al. Management of digestive fistulas. Scand J Gastroenterol 29: 42-44, 1994. Suppl 207

25 - NUBIOLA P et al. Treatment of postoperative enterocutaneous fistulas with the long half-life somatostatin analogue SMS 201-995. Ann Surg 210: 56-58, 1989.

26 - CASTAÑON GONZALES JA et al. The somatostatin analogue SMA 201-995 as adjuvant treatment in patients with external fistulae of the digestive system. Gac Med Mex 128: 285-288, 1992

27 - PARAN H et al. Octreotide for treatment of postoperative alimentary tract fistulas. World J Surg 19: 430-433, 1995.

28 - CAMPOS ACL. Modelo multivariado para determinação de fatores prognósticos nas fístulas digestivas. Tese de Titular. Setor de Ciências da Saúde da Universidade Federal do Paraná. Curitiba, 1995.

29 - JORGE FILHO I. Fístulas digestivas:(B) Fístulas jejunoileais. In: COELHO J. Aparelho digestivo: Clínica e cirurgia. $2^{a}$ ed., Medsi, Rio de Janeiro, p.442-449, 1996.

30 - RASSLAN S et al. Fístulas pós-operatórias. In: RASSLAN S. Aspectos críticos do doente cirurgico. Robe, São Paulo, p.161-171, 1988.

31 - ROSE D et al. One hundred and fourteen fistulas of the gastrointestinal tract treated with total parenteral nutrition. Surg Gynecol Obstet 163: 345-350, 1986.

Recebido para publicação em 04/03/98

Aprovado para publicação em 07/10/98 